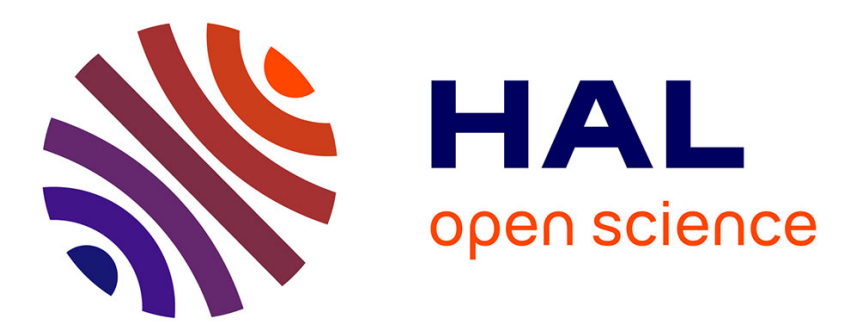

\title{
Delaying the introduction of emissions trading systems-Implications for power plant investment and operation from a multi-stage decision model
}

\author{
Jian-Lei Mo, Joachim Schleich, Lei Zhu, Ying Fan
}

\section{To cite this version:}

Jian-Lei Mo, Joachim Schleich, Lei Zhu, Ying Fan. Delaying the introduction of emissions trading systems-Implications for power plant investment and operation from a multi-stage decision model. Energy Economics, 2015, 52, pp.255-264. 10.1016/j.eneco.2015.11.009 . hal-01265934

\section{HAL Id: hal-01265934 \\ http://hal.grenoble-em.com/hal-01265934}

Submitted on 1 Feb 2016

HAL is a multi-disciplinary open access archive for the deposit and dissemination of scientific research documents, whether they are published or not. The documents may come from teaching and research institutions in France or abroad, or from public or private research centers.
L'archive ouverte pluridisciplinaire HAL, est destinée au dépôt et à la diffusion de documents scientifiques de niveau recherche, publiés ou non, émanant des établissements d'enseignement et de recherche français ou étrangers, des laboratoires publics ou privés. 


\title{
Delaying the introduction of emissions trading systems - Implications for power plant investment and operation from a multi-stage decision model
}

\author{
Jian-Lei Mo ${ }^{\mathrm{a}}$, Joachim Schleich ${ }^{\mathrm{b}, \mathrm{c}, \mathrm{d}}$, Lei Zhu ${ }^{\mathrm{a}}$, Ying Fan ${ }^{\mathrm{a}}$, \\ ${ }^{a}$ Center for Energy and Environmental Policy Research, Institute of Policy and Management, \\ Chinese Academy of Sciences, Beijing 100190, China \\ ${ }^{\mathrm{b}}$ Fraunhofer Institute for Systems and Innovation Research, Karlsruhe 76139, Germany \\ ${ }^{\mathrm{c}}$ Grenoble Ecole de Management, 12, rue Pierre Sémard - BP 127 - 38003 Grenoble, France \\ ${ }^{\mathrm{d}}$ Virginia Polytechnic Institute \& State University, 24061 Blacksburg, Virginia, USA \\ *Corresponding author: Ying Fan, E-mail: yfan@casipm.ac.cn, ying_fan@263.net
}

\begin{abstract}
Relying on real options theory, we employ a multistage decision model to analyze the effect of delaying the introduction of emission trading systems (ETS) on power plant investments in carbon capture and storage (CCS) retrofits, on plant operation, and on carbon dioxide (CO2) abatement. Unlike previous studies, we assume that the investment decision is made before the ETS is in place, and we allow CCS operating flexibility for new power plant investments. Thus, the plant may be run in CCS-off mode if carbon prices are low. We employ Monte Carlo simulation methods to account for uncertainties in the prices of $\mathrm{CO}_{2}$ certificates, other inputs, and output prices, relying on a realistic parameterization for a supercritical pulverized coal plant in China. We find that CCS operating flexibility lowers the critical carbon price needed to support CCS investment because it renders CCS investment less irreversible. For a low carbon price path, operating flexibility also implies that delaying the introduction of an ETS hardly affects plant $\mathrm{CO}_{2}$ abatement since the plant operator is better off purchasing emission certificates rather than operating the plant in CCS mode. Interestingly, for low carbon prices we find a U-shaped relation between the length of the delay and the economic value of the plant. Thus, delaying the introduction of an ETS may make investors worse off.
\end{abstract}

Key words: power plant investment; regulatory uncertainty; multistage decision, operating flexibility; real options theory; emissions trading; CCS; China 


\section{Introduction}

Following the introduction of the EU Emissions Trading System (ETS) in 2005, many emerging and developed countries are planning to introduce similar ETS in the future (IEA, 2010; The World Bank, 2014). However, several of these countries are hesitant with regard to whether and when they will implement such a system. Among others, their future climate targets are unknown, due in part to the slow progress of the United Nations' climate negotiations. In addition, countries are considering alternative domestic policies, because implementing an ETS is a highly complex process, requiring new institutions that challenge existing regulatory and organizational practices.

For example, China, the world's largest emitter of greenhouse gases, has undertaken substantial efforts to mitigate carbon dioxide $\left(\mathrm{CO}_{2}\right)$ emissions (National Development and Reform Commission [NDRC], 2012) and is considering implementing a national ETS in the future, depending on, among other things, the success of seven local pilot carbon markets, which are being built during the Twelfth Five-Year Plan (2011-2015) (People's Republic of China [PRC], 2011; see also NDRC, 2011). Because the outcome of these pilot markets is not yet known and because China, like many other countries, prefers to take on more ambitious greenhouse gas targets under the United Nations Framework Convention later rather than sooner, the future of a national ETS in China is highly uncertain (Jotzo, 2013; Wang, 2012).

This regulatory uncertainty affects investment decisions in the electricity sector, in particular. The electricity sector contributes more than $41 \%$ of the total energy-related $\mathrm{CO}_{2}$ emission of the world, and $50.1 \%$ for China (IEA, 2013a). As such, power plants are included in all foreseeable ETS. Carbon capture and storage (CCS) technology is critical for realizing large-scale reductions in $\mathrm{CO}_{2}$ emissions in the power sector and thus for meeting ambitious emission targets (IEA, 2007b; 2013b). According to the IEA (2015), CCS contributes $13 \%$ of the cumulative emission reduction required to meet the $2{ }^{\circ} \mathrm{C}$ target compared to the business-as-usual $6^{\circ} \mathrm{C}$ scenario. The mitigation cost without CCS would increase by $138 \%$. Yet adding CCS to any process increases the capital costs required to capture, compress, transport, and store $\mathrm{CO}_{2}$. Operating costs also increase, particularly because CCS implies a loss in production efficiency. Finally, CCS technology suffers from a lack of social acceptance and regulatory framework (e.g., for sequestration) in many countries. Thus, investors in CCS currently face substantial market, policy, and technology uncertainties (e.g., Hirschhausen et al. 2012, IEA 2007a). Because of the high capital expenditure and the irreversibility of the CCS investment, potential plant investors may prefer delaying CCS investments (Abadie and Chamorro, 2008). Likewise, because of higher operating costs, plant operators may prefer to suspend CCS operations even after the plant has been retrofitted with CCS technology (Davison 2007; Mo and Zhu, 2014). Compared with a regulation involving technology standards or a carbon tax, an ETS introduces additional uncertainty, because the price of $\mathrm{CO}_{2}$ certificates is determined by the market and is not known with certainty in advance.

In this paper, we model investments in new power plants and operating the plant as a long-term, multistage decision problem, in which the decision at each stage may be affected by the decision in the preceding stage (e.g., Markusson and Haszeldine, 2010). In the first stage, before a regulation (in our case, implementation of an ETS) is introduced, the investor (e.g., utility) invests in a new power plant; in the second stage, after the regulation becomes known, the utility decides 
whether to retrofit the plant with CCS; in the third stage, once input and output prices are known, the utility decides whether to operate the CCS unit or to suspend operating CCS temporarily. At each stage, the utility may also decide to close the plant for good.

Few scholars have evaluated the effect of climate policy uncertainty on investments in fossil-fuelled power plants. Blyth et al. (2007) demonstrate that uncertainty about future climate policy creates a risk premium which increases the carbon price required to stimulate investment in CCS. Employing a real options approach, Yang et al. (2008) find that climate policy risk can become significant if there is a short time between a future climate policy event and the time when the investment decision is made. By implementing credible long-term climate change policy, the government can reduce this risk. Abadie and Chamorro (2008), among others, point out that installing a CCS unit in a coal-fired power plant operating in a carbon-constrained environment is not profitable under current climate policy. Walsh et al. (2014) use an analytic real options model with time-dependent investment costs to investigate the timing of CCS investment. Their findings suggest that higher carbon price volatility increases the critical carbon price, i.e. the price of carbon above which investment must be made immediately rather than keeping the option to invest open. Zhang and Wei (2011) present a real options-based carbon capture investment model to investigate the timing of investments while allowing for uncertainty in carbon prices and in the CCS technology. They find that the prospects of technological improvements in CCS will delay investment. Also relying on a real options-based model, Zhu and Fan (2011) conclude that the current investment risk of CCS is high and that climate policy uncertainty has a greater effect on CCS development in China than uncertainty related to investment or fuel input costs. Zhang et al. (2014) employ a trinomial tree model based on real options theory to calculate critical carbon prices for investment in CCS retrofit in China. Fleten and Näsäkkälä (2010) analyze investments in gas-fired power plants, considering the significant uncertainty in future market prices for fuel and $\mathrm{CO}_{2}$, as well as in future investment and operating flexibility. Allowing for stochastic prices of electricity and natural gas, they show that operating flexibility may significantly affect the decision to invest in a new plant. Models allowing for operating flexibility also reflect real-world CCS plant operation more adequately (e.g., Chalmers et al. 2009). Mo and Zhu (2014) develop a model for investment in CCS retrofits of existing plants in which carbon capturing can be switched off to analyze the impact of a carbon price-floor policy on CCS investment and $\mathrm{CO}_{2}$ abatement. Based on a multi-factor real options model Rohlfs and Madlener (2011) find that low carbon prices in particular render investment in carbon-capture-ready (CCR) plants less attractive than investment in a conventional plant with a later retrofit. Finally, Xun et al. (2014) rely on a real options model with multiple uncertainties to derive the optimal technology choice among the competing generation technologies CCS, combined cycle gas turbine (CCGT), wind power and nuclear under different market conditions.

Using China as an exemplary case study, we simulate how the timing of introducing $\mathrm{CO}_{2}$ emission regulation affects the economic value of the investment, as well as an investor's decision to retrofit CCS and to operate CCS. In particular, we explore whether delayed regulation makes investors better or worse off. Although our methodology relies on real options theory, allowing for stochastic (and correlated) prices of electricity, coal, and $\mathrm{CO}_{2}$ certificates, our approach differs from the extant literature in two important respects. First, we assume that the power plant investment occurs before the regulation is in place, which is a realistic scenario for many projects. 
Second, in addition to allowing for flexibility in the timing of the CCS investment and the option to close the plant permanently, our model allows for CCS operating flexibility. ${ }^{1}$ These features add complexity but allow for some novel insights. First, we find that CCS operating flexibility lowers the critical carbon price and is thus conducive to investing in CCS power plants. Second, delaying the introduction of the ETS hardly affects $\mathrm{CO}_{2}$ abatement if the carbon price is low. Third, we find a $\mathrm{U}$-shaped relation between the economic value of the new plant and the length of the delay of ETS. Thus, a delay in the ETS may actually make investors worse off, which is counterintuitive at first.

We organize the remainder of this article as follows: In Section 2, we develop a generic real-options-theory-based model, governing power plant investment and operating decisions under multiple uncertainties. In Section 3, we present the key assumptions for power plant investments in China, which enter our simulations. In Section 4, we present and discuss the simulation results, and in Section 5, we offer some concluding remarks.

\section{Modeling power plant investment under uncertainty}

In our model, the utility is assumed to make decisions about its investment in and operation of the plant in each period to maximize the economic value of the project, while under uncertainty. The plant lifetime can be divided into three stages, as shown in Figure 1. Timing flexibilities on decommissioning the plant in advance and retrofitting the plant with $\mathrm{CCS}^{2}$, as well as CCS operating flexibility were incorporated. In Stage 1, at the beginning of the plant lifetime in period $\mathrm{T}_{0}$, the utility invests in a new power plant. Construction of the plant is assumed to take two years until completion in $\mathrm{T}_{1}$. A CO $\mathrm{CO}_{2}$ emission regulation (i.e., ETS) will be introduced in $\mathrm{T}_{2}$. Between $\mathrm{T}_{1}$ and $\mathrm{T}_{2}$, the utility may decide to decommission the plant in advance if it anticipates that ongoing operations of the plant will lead to a negative cash flow in the future. In Stage 2, from $T_{2}+1$ onward, the plant operator first decides whether to decommission the power plant. If the plant is not decommissioned, the utility decides whether to retrofit the plant with CCS immediately or delay the retrofit until some time $\mathrm{T}_{\mathrm{r}}^{3}\left(\mathrm{~T}_{2} \leftarrow \mathrm{T}_{\mathrm{r}} \leftarrow \mathrm{T}\right)$. In Stage 3, after the CCS retrofit is implemented (i.e., from $T_{r}+1$ to $T$ ), at the beginning of each period, the utility decides whether to decommission the plant. If the plant is not decommissioned, it decides whether to operate the plant in CCS mode or in non-CCS mode. Next, we present the formal decision problem backward, starting with the final stage.

\footnotetext{
${ }^{1}$ Apart from the timing of the investment decision, our model differs from Mo and Zhu (2014) in other important facets. In particular, we built a three-stage model to analyse investment in a new power plant, while Mo and Zhu (2014) employ a two-stage decision model to explore CCS retrofit to an existing power plant.

2 Timing flexibility means that the utility can chose the optimal point in time to implement a decision in order to maximize the economic value of the investment (e.g. decommission the plant, or retrofit the plant with CCS), by repeating the decision on whether to implement it immediately or to delay in each period of the respective stage until the utility either finds the optimal point in time, or gives up the option at the end of the respective stage. The timing flexibility to retrofit the plant with CCS is only valid during the second stage. The timing flexibility on whether and when to decommission the plant exists during the entire lifetime of the plant after the plant is constructed.

${ }^{3}$ We assume the utility invests in a CCS retrofit in period $\mathrm{T}_{\mathrm{r}}$ and that the retrofit takes one year to be completed.
} 
Figure 1. The power plant's investment and operation decision process (The decision process during the lifetime of a power plant is modeled in three stages, and the decision at each stage is affected by the electricity, fuel and carbon markets.)

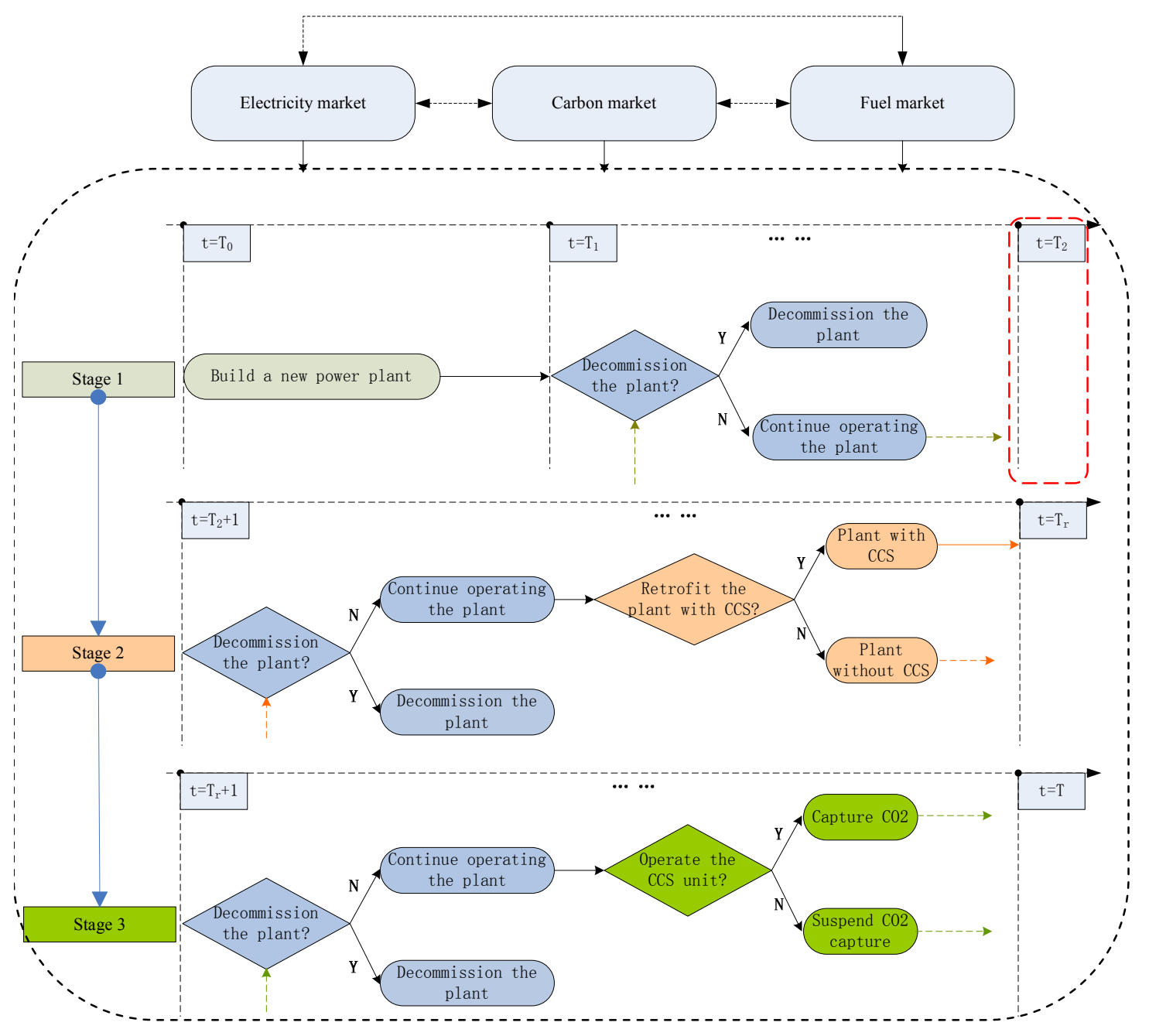

\subsection{Stage 3: From $T_{r}+1$ to $T$}

From $T_{r}+1$ onward, similar to the previous stages, the utility may first decide whether to decommission the plant in advance in any period, and, if not, the utility may decide whether to operate the plant in CCS mode or not. The utility repeats these two decisions in each period until the plant is decommissioned or the end of stage 3 is reached. The utility is assumed to maximize the net cash flow in each period. The decision problem for each period in Stage 3 then becomes:

$\left\{\begin{array}{l}\text { Capature } \mathrm{CO}_{2} \text {, if } \mathrm{CF}_{t}^{s c c}<\mathrm{CF}_{t}^{c c} \\ \text { Suspend } \mathrm{CO}_{2} \text { Capature, if } \mathrm{CF}_{t}^{s c c} \geq C F_{t}^{c c}\end{array}\right.$

where $C F_{t}^{C C}$ and $C F_{t}^{S C C}$ are the cash flows when operating in CCS mode and non-CCS mode, respectively, in period $t^{4}$ The optimized cash flow is then

\footnotetext{
${ }^{4}$ It is assumed that the cost of switching between the operation modes is zero. Appendix A details the calculation
} 


$$
C F_{t}=\operatorname{MAX}\left(C F_{t}^{S C C}, C F_{t}^{C C}\right)
$$

The utility closes the plant in period $t$ if the expected net present value (NPV) of net cash flow from continuing to operate the plant, $V_{t}^{3}$, is less than the NPV from decommissioning the plant, $N P V_{t}^{A} 5$

$\left\{\begin{array}{l}\text { Decommission the plant, if } E_{t}\left(V_{t}^{3}\right) \leq N P V_{t}^{A} \\ \text { Continue operating the the plant, if } E_{t}\left(V_{t}^{3}\right)>N P V_{t}^{A} \quad\left(\mathrm{~T}_{r}+1 \geq \mathrm{t} \geq \mathrm{T}\right) .\end{array}\right.$

Here, $V_{t}^{3}$ can be expressed as

$V_{t}^{3}=C F_{t}+e^{-r \Delta t} \operatorname{MAX}\left(N P V_{t+\Delta t}^{A}, E_{t}\left(V_{t+\Delta t}^{3}\right)\right)$,

where $r$ is the discount rate, and $\Delta t$ is the time step. The optimized economic value in period $t$ is $F_{t}^{3}=\operatorname{MAX}\left(N P V_{t}^{A}, E\left(V_{t}^{3}\right)\right)$.

Equation 5 then becomes the basis for the decision about whether to retrofit the plant with CCS in

Stage 2. The boundary condition of $V_{t}^{3}$ in the last period $\mathrm{T}$ is

$V_{T}^{3}=C F_{T}$

The boundary condition in Equation 6 allows $V_{t}^{3}$ and $F_{t}^{3}$ to be solved backward.

\subsection{Stage 2: From $T_{2}+1$ to $T_{r}$}

Unless the utility decides to decommission the plant, it must decide whether to retrofit the plant with CCS immediately or to delay the retrofit. In the latter case, the utility pays for all $\mathrm{CO}_{2}$ emissions in that period. If the utility invests in CCS in period $t$ (from $T_{2}+1$ to $T_{r}$ ), the total NPV is

$$
N P V_{t}=e^{-r} F_{t+1}^{3}-C_{t}^{C C S-o u t l a y},
$$

where $C_{t}^{C C S-o u t l a y}$ is the investment cost of a CCS retrofit in period $t$, and $F_{t+1}^{3}$ is the expected NPV of the future net cash flow from period $(t+1)$ to $T$, after retrofitting the power plant (Equation 5). If the utility delays the retrofit, the total NPV of the investment opportunity becomes $V_{t}^{2}=C F_{t}^{B R}+e^{-r \Delta t} \operatorname{MAX}\left(N P V_{t+\Delta t}, E_{t}\left(V_{t+\Delta t}^{2}\right)\right)$,

where $C F_{t}^{B R}$ is the cash flow before a CCS retrofit in period $t$ and after the government

of net cash flow in each period, $C F_{t}^{C C}$ and $C F_{t}^{S C C}$.

5 These decision rules are based on a dynamic real options approach (and not on a myopic NPV approach), and the timing flexibility and hysteresis effect are taken into account. Similarly, the decision rules in (9), (11), and (15) also employ the dynamic real options approach. For simplicity, we further assume that decommissioning the plant yields a net cash flow of 0 . 
introduced an ETS in $\mathrm{T}_{2}{ }^{6}$ The CCS retrofit investment in Stage 2 then is governed by the following decision rule for each $t$ :

$\left\{\begin{array}{l}\text { Retrofit plant with CCS immediately, if } E_{t}\left(N P V_{t}\right)>E_{t}\left(V_{t}^{2}\right) \\ \text { Delay the CCS retrofit, if } E_{t}\left(N P V_{t}\right) \leq E_{t}\left(V_{t}^{2}\right)\end{array}\right.$.

In each period, decisions are made based on the prices in that period and the carbon price trajectories by comparing $E_{t}\left(N P V_{t}\right)$ and $E_{t}\left(V_{t}^{2}\right)$.

The optimized economic value from continuing operating the plant in period $t$ is

$f_{t}^{2}=\operatorname{MAX}\left(E_{t}\left(N P V_{t}\right), E_{t}\left(V_{t}^{2}\right)\right)$.

The decision rules for whether to decommission the plant become

$\left\{\begin{array}{l}\text { Decommission the plant, } \quad \text { if } f_{t}^{2} \leq N P V_{t}^{A} \\ \text { Continue operating the plant, if } f_{t}^{2}>N P V_{t}^{A}\end{array}\right.$.

Then, the optimized economic value in period $t$ in Stage 2 is

$F_{t}^{2}=\operatorname{MAX}\left(f_{t}^{2}, N P V_{t}^{A}\right)$.

Equation 12 allows us to derive the optimized economic value at time $\left(T_{2}+\Delta t\right), F_{T_{2}+\Delta t}^{2}$, which the utility takes into account when making a decision in Stage 1.

At time $\mathrm{T}$, the utility has no incentive to invest in a CCS retrofit, because there is no time to recover the investment cost. Then, the total expected NPV from delaying the CCS investment at time $\mathrm{T}, V_{T}^{2}$, is (boundary condition)

$V_{T}^{2}=\operatorname{MAX}\left(0, C F_{T}^{B R}\right)$

where $C F_{T}^{B R}$ is the cash flow in period T before the CCS retrofit. Equation 13 allows us to solve for $V_{t}^{2}, f_{t}^{2}$, and $F_{t}^{2}$ backward.

\subsection{Stage 1: From $T_{0}$ to $T_{2}$}

In Stage 1, the utility first makes an investment in the power plant at $\mathrm{T}_{0}$ and finishes construction in period $\mathrm{T}_{1}$. Then, the utility has the option to decide whether to decommission the plant at the beginning of each period. In period $t\left(T_{1} \leq t \leq T_{2}\right)$, continuing to operate the plant yields an NPV of $V_{t}^{1}$ :

$V_{t}^{1}=C F_{t}^{B E T S}+e^{-r \Delta t} M A X\left(N P V_{t+\Delta t}^{A}, E_{t}\left(V_{t+\Delta t}^{1}\right)\right)$

\footnotetext{
${ }^{6}$ Appendix A details the calculation of $C F_{j}^{B R}$.
} 
where $C F_{t}^{B E T S}$ is the cash flow in period $t$ before the ETS is introduced. ${ }^{7}$ Note that in each period during this stage, there is no $\mathrm{CO}_{2}$ emission regulation. The decision about whether to decommission the plant after it has been built but before $\mathrm{T}_{2}$ when the $\mathrm{CO}_{2}$ ETS is introduced is as follows:

$\left\{\begin{array}{l}\text { Decommission the plant, if } E_{t}\left(V_{t}^{1}\right) \leq N P V_{t}^{A} \\ \text { Continue operating the plant, if } E_{t}\left(V_{t}^{1}\right)>N P V_{t}^{A}\end{array}\right.$.

The optimized economic value in each period $t$ is

$F_{t}^{1}=\operatorname{MAX}\left(E_{t}\left(V_{t}^{1}\right), N P V_{t}^{A}\right)$.

From Equation 16, we can derive the optimized economic value at time $\mathrm{T}_{1}, F_{T_{1}}^{1}$. The boundary condition in period $\mathrm{T}_{2}$ is then

$V_{T_{2}}^{1}=C F_{T_{2}}^{B E T S}+e^{-r \Delta t} F_{T_{2}+\Delta t}^{2}$,

where $F_{T_{2}+\Delta t}^{2}$ is obtained from Stage 2 (Equation 12).

In period $\mathrm{T}_{0}$, the economic value of the power plant investment is $S_{T_{0}}{ }^{8}$ :

$S_{T_{0}}=-C_{T_{0}}+e^{-r\left(T_{1}-T_{0}\right)} F_{T_{1}}^{1}$

where $C_{T_{0}}$ is the investment cost of the plant, and $F_{T_{1}}^{1}$ can be obtained from Equation 16.

\section{Description of the case study}

For the case study simulations, we chose a supercritical pulverized coal (SCPC) plant investment, which is a promising technology option for China's electricity sector (Chen and $\mathrm{Xu}, 2010$; Deng, 2008; Huang, 2008). The relevant technical parameters of the plant appear in Table 1.

Investors in power plants face uncertain future costs and revenues. In particular, electricity prices, coal prices, and $\mathrm{CO}_{2}$ certificate prices are assumed to follow stochastic processes. Like Davis and Owens (2003), Siddiqui et al. (2007), and Kumbaroğlu et al. (2008), we model coal prices as a geometric Brownian motion (GBM). ${ }^{9}$ In a liberalized electricity market, the electricity price is characterized by mean reversion, seasonality, and stochastic volatility (Schwartz and Smith, 2000). Thus, the long-term development of electricity prices in a mature electricity market may be described best with a mean-reverting stochastic process. However, because the model eventually

\footnotetext{
7 Appendix A details the calculation of net cash flow in each period, $C F_{k}^{B E T S}$.

${ }^{8}$ Economic value here means the expanded NPV which is the sum of the traditional NPV and the value of management flexibility (Dixit and Pindyck, 1994).

9 According to Pindyck (1999), who analyzes the long-term evolution of energy prices such as oil, coal, and natural gas, using a GBM model is unlikely to lead to large errors in optimal investment rules, even though long-term energy prices may be mean-reverting.
} 
will be applied to China, where the electricity market is still regulated, we employ GBM rather than a mean-reverting process to model the electricity price development. ${ }^{10}$ The $\mathrm{CO}_{2}$ certificate price in the Chinese ETS pilots is currently relatively low $^{11}$ but is expected to increase gradually once allocation becomes more stringent in the middle and long term, as China takes on more ambitious national emissions targets. In addition, $\mathrm{CO}_{2}$ certificate price evolution is subject to many factors, reflecting uncertainty in both supply and demand that influences the $\mathrm{CO}_{2}$ certificate price (Alberola et al., 2008; Benz and Trück, 2009). We therefore follow prior literature (Abadie and Chamorro 2008; Fuss et al., 2008; Zhou et al., 2010; Zhu and Fan, 2011) and model the future $\mathrm{CO}_{2}$ certificate price evolution as a GBM process. In addition, we consider correlations across different price evolutions. The equations of uncertain price evolution are in Appendix B; the relevant economic parameters appear in Table 2.

The current average carbon price in the seven ETS pilot schemes in China is approximately 50 $\mathrm{RMB} / \mathrm{t} \mathrm{CO}_{2}$. However, the carbon price parameters cannot be obtained on the basis of historical price development, because carbon markets in China are still young. Following Rohlfs and Madlener (2011) and Abadie and Chamorro (2008), we set the drift rate of the certificate price in the base case at $4 \%$. Because this parameter significantly affects the outcomes of our simulations, we also consider scenarios with drift rates of $1 \%$ (low case) and 7\% (high case). For the subsequent simulations, we assume the planning horizon ranges from 2015 to 2050 . We chose 2015 as the starting year, because it is the earliest year a national ETS in China is likely to be implemented.

To solve the model, we employ Monte Carlo simulation methods and the least squares methods, as proposed by Longstaff and Schwartz (2001). Brauneis et al. (2013) and Mo and Zhu (2014), among others, use a similar approach (Appendix C provides the details).

\footnotetext{
${ }^{10}$ Electricity prices in China are currently low, but they are expected to increase in the wake of future market reforms (Fan et al., 2013; Mo et al., 2013).

${ }^{11}$ Until the end of October 2014, the average $\mathrm{CO}_{2}$ prices in the seven pilot schemes in China ranged from 20 to 70 $\mathrm{RMB} / \mathrm{t} \mathrm{CO}$, with Shenzhen at $69.5 \mathrm{RMB} / \mathrm{t} \mathrm{CO} 2$ (8.95 Euros/t $\left.\mathrm{CO}_{2}\right)$, Shanghai at $39.1 \mathrm{RMB} / \mathrm{t} \mathrm{CO} \mathrm{CO}_{2}(5.04$ Euros/t $\mathrm{CO}_{2}$ ), Beijing at $49.5 \mathrm{RMB} / \mathrm{t} \mathrm{CO} 2\left(6.38\right.$ euros/t $\left.\mathrm{CO}_{2}\right)$, Tianjin at $20.7 \mathrm{RMB} / \mathrm{t} \mathrm{CO} 2\left(2.66\right.$ euros/t $\left.\mathrm{CO}_{2}\right)$, Chongqing at $29.7 \mathrm{RMB} / \mathrm{t} \mathrm{CO}_{2}\left(3.83\right.$ euros/t $\left.\mathrm{CO}_{2}\right)$, Guangdong at $54.2 \mathrm{RMB} / \mathrm{t} \mathrm{CO}_{2}\left(6.99\right.$ euros/t $\left.\mathrm{CO}_{2}\right)$, and Hubei at $23.8 \mathrm{RMB} / \mathrm{t}$ $\mathrm{CO}_{2}$ (3.07 euros/t $\mathrm{CO}_{2}$ ).
} 
Table 1. Technical parameters for power plant investment

\begin{tabular}{|c|c|c|c|}
\hline Parameters & & Unit & Value \\
\hline Installed capacity & & MW & 600 \\
\hline Construction cycle & & years & 2 \\
\hline Average capacity load & & $\%$ & 85 \\
\hline Plant lifetime & & years & 35 \\
\hline Emission factor & & $\mathrm{t} \mathrm{CO}_{2} / \mathrm{MWh}$ & 0.79 \\
\hline Initial capital outlay & & M RMB & 3165.8 \\
\hline Additional capital outlay for CCS retrofit & & M RMB & 1449.9 \\
\hline Initial operation and maintenance $(\mathrm{O} \& \mathrm{M})$ cost & & $\mathrm{M} \mathrm{RMB} / \mathrm{y}$ & 165.3 \\
\hline Additional O\&M cost for CCS operation & & M RMB/y & 115.7 \\
\hline Initial power supply efficiency & & $\%$ & 42 \\
\hline Efficiency penalty with CCS & & percentage points & 9.5 \\
\hline $\mathrm{CO}_{2}$ capture rate & & $\%$ & 80 \\
\hline Costs for transport, storage, and monitoring & & $\mathrm{RMB} / \mathrm{t} \mathrm{CO}_{2}$ & 50 \\
\hline Time needed for CCS retrofit & & year & 1 \\
\hline \multicolumn{4}{|c|}{$\begin{array}{l}\text { Data sources: Sekar (2005), Abadie and Chamorro (2008), Liang et al. (2009), Rohlfs and Madlener (2011), an } \\
\text { Mo and Zhu (2014). }\end{array}$} \\
\hline \multicolumn{4}{|l|}{ Table 2. Economic parameters } \\
\hline Parameters & & Unit & Value \\
\hline Initial electricity price & & RMB/MWh & 600 \\
\hline Initial coal price & & $\mathrm{RMB} / \mathrm{M}$ Btu & 27.5 \\
\hline Risk-adjusted electricity price drift rate & & $\%$ & 3 \\
\hline Risk-adjusted coal price drift rate & & $\%$ & 3 \\
\hline Electricity price volatility & & $\%$ & 8 \\
\hline Coal price volatility & & $\%$ & 10 \\
\hline Initial carbon price & & $\mathrm{RMB} / \mathrm{t} \mathrm{CO} 2$ & 50 \\
\hline \multirow{3}{*}{ Risk-adjusted carbon price drift rate } & High case & $\%$ & 1 \\
\hline & Base case & $\%$ & 4 \\
\hline & Low case & $\%$ & 7 \\
\hline Carbon price volatility & & $\%$ & 25 \\
\hline \multirow{3}{*}{ Correlation coefficient } & Electricity-coal & - & 0.6 \\
\hline & Electricity-carbon & - & 0.395 \\
\hline & Coal-carbon & - & -0.35 \\
\hline Discount rate & & $\%$ & 5 \\
\hline Time step length in simulation & & Year & $1 / 4$ \\
\hline Number of simulated paths & & - & 10000 \\
\hline
\end{tabular}

Data sources: Abadie and Chamorro (2008), Liang et al. (2009), Zhu and Fan (2011), and Rohlfs and Madlener (2011).

Note: 1) We have checked the correlation coefficient matrix for positive semi-definiteness. 2) Following Zhu and Fan (2011), we employ a low electricity price volatility since the power market in China is still regulated by the government. 


\section{Simulation results}

Our presentation of the simulation results focuses on how the timing of the introduction of an ETS affects power plant investments and operating decisions. Of particular interest are the consequences for $\mathrm{CCS}$ retrofit, $\mathrm{CO}_{2}$ abatement, and the value of the power plant investment.

\subsection{CCS retrofit}

The multistage decision model implies that a delay in introducing an ETS also changes the CCS retrofit decision. Figure 2 shows the probability distribution of the time when the plant is retrofitted with CCS for different periods of introducing an ETS $(2015,2025,2035,2045)$ and the drift rate of the future carbon price is set at its base case level of $4 \%$. The solid line is the cumulative probability, and the dotted line represents the marginal probability. First, the probability to invest in CCS before the ETS is introduced is zero, because the utility has no incentive to abate $\mathrm{CO}_{2}$. Second, as expected, a delay in the ETS shifts the probability distribution to the right (i.e., the plant will be retrofitted later). Third, there is a peak value of the marginal probability for when the ETS is introduced, and the marginal probability drops rapidly afterward. The CCS retrofit mainly occurs at an early stage after the $\mathrm{CO}_{2}$ emission regulation is introduced, because the power plant lifetime is limited, and there will not be enough time left to operate profitably in CCS mode if the plant is retrofitted too late. If the current carbon price is very low and the future carbon price increases rapidly, the CCS retrofit might occur later. However, our simulation results suggest that this probability is rather small. Finally, our simulations illustrate how the cumulative probability decreases with the time of introducing an ETS. For example, the probability would decrease by nearly $10 \%$, from $85.7 \%$ to $77.1 \%$, if the introduction of an ETS were delayed by 10 years, from 2020 to $2030 .^{12}$

Figure 2. The probability distribution of CCS retrofit time (Early implementation of an ETS promotes CCS retrofit; most CCS retrofits occur shortly after an ETS is implemented.)

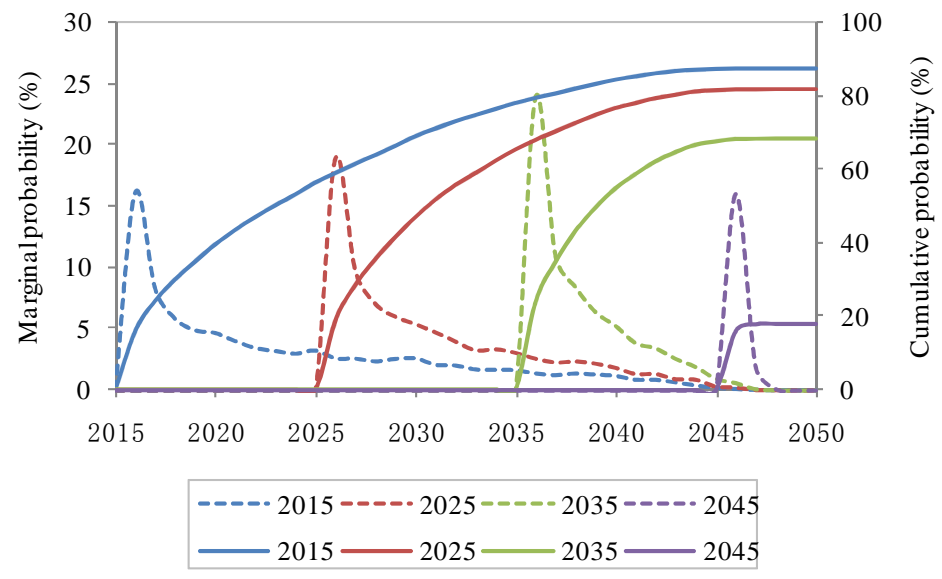

\footnotetext{
${ }^{12}$ This example mimics discussions at the UNFCCC level about whether China should take on emission targets in 2020 or in 2030.
} 
To explore the impact of the carbon market evolution further, we simulate the probability of a CCS retrofit for different carbon price drift rates. Figure 3 (left) illustrates how the probability of a CCS retrofit in Stage 2 would change with a higher or lower carbon price drift rate, compared with the base case. Because a higher carbon price drift rate means a higher carbon price and thus higher $\mathrm{CO}_{2}$ emission costs in the future, a CCS retrofit investment becomes more valuable. The reverse holds for a lower drift rate. Figure 3 (right) shows the differences in the probabilities of a CCS retrofit for different carbon price scenarios: The probability difference increases when an ETS is introduced later. If the ETS is introduced later, the effect of the future carbon price on the CCS retrofit decision thus is greater.

Figure 3. The CCS retrofit decision with CCS operating flexibility (Higher carbon price drift rates promote CCS retrofits; the impacts of carbon prices on CCS retrofit are stronger the later the ETS is implemented.)
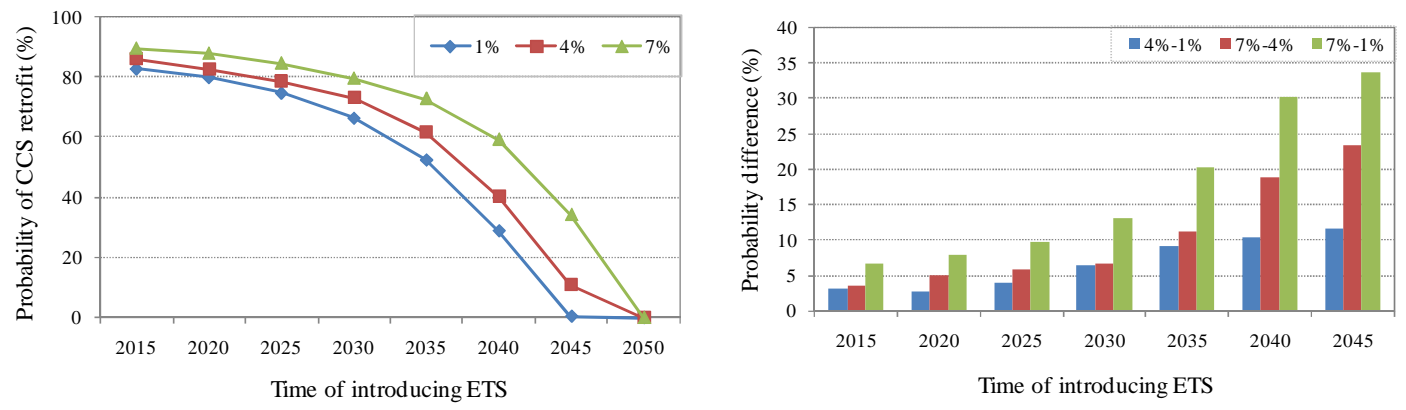

To further explore the impact of CCS operating flexibility on CCS retrofit decisions, we also derive the retrofit probabilities for a plant without CCS operating flexibility (Figure 4). Similar to the results with operating flexibility (Figure 3), the probability of a CCS retrofit decreases with the ETS being delayed and increases with higher carbon prices. Comparing the results in Figure 4 and Figure 3 (right) shows that the probability of a CCS retrofit is much higher with operating flexibility than without operating flexibility. Taking the case of a $1 \%$ carbon price drift rate as an example, the probability of a CCS retrofit over the period 2015 to 2050 is about $80 \%$ with operating flexibility when the ETS is introduced in 2015. For a CCS plant without operating flexibility, this probability is only about $40 \%$. This illustrates that CCS operating flexibility increases the likelihood of a CCS retrofit. According to the real options theory, because of the irreversibility of the CCS investment, potential investors are prone to defer or even give up CCS investment when faced with future uncertainty (Dixit and Pindyck, 1994). However, if the carbon capture is flexible, and the investors can switch off CCS operation when the carbon price is too low, the profitability increases (Abadie and Chamorro, 2008). Since operating flexibility renders the investment less irreversible, investors are prone to make more investment in CCS than if there was no CCS operating flexibility. 
Figure 4. The CCS retrofit decision without CCS operating flexibility (Comparing the results between Figure 4 and Figure 3 shows that CCS operating flexibility increases the likelihood of CCS retrofit.)

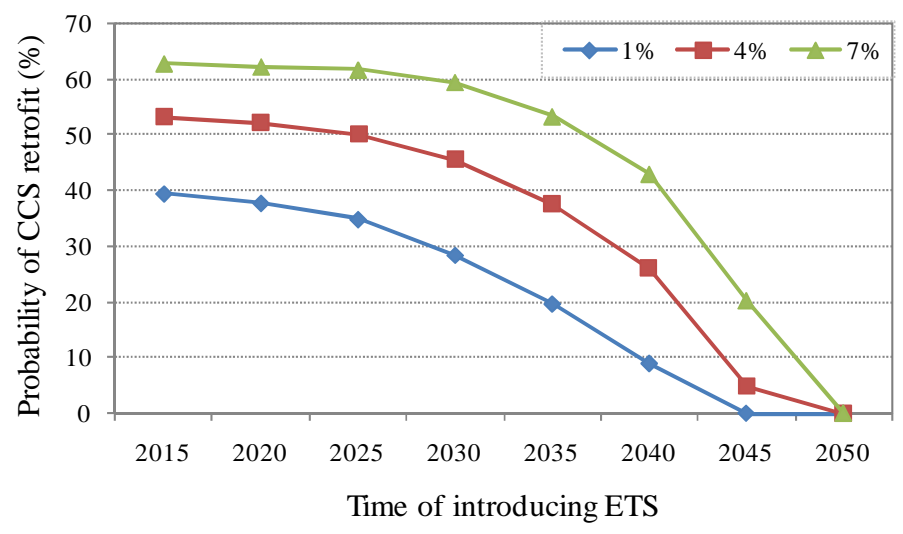

Based on the results of CCS retrofit decisions, we can also calculate the threshold value for the initial carbon price which would render investment in CCS almost certain (e.g. with $90 \%$ probability). Figure 5 displays the critical carbon price for the base case drift rate of the carbon price given different points in time of introducing an ETS. More specifically, if the ETS is introduced in 2015, the critical carbon price above which the CCS retrofit probability is $90 \%$ is about $140 \mathrm{RMB} / \mathrm{tCO}_{2}$. For lower (higher) CCS investment probability levels, the critical carbon price would also be lower (higher). For example, if the investment probability is set to $80 \%$, the critical carbon price would amount to $103 \mathrm{RMB} / \mathrm{tCO}_{2}$. Likewise, as can be seen in Figure 5, the critical carbon price would increase with the introduction of ETS being delayed, and it reaches $350 \mathrm{RMB} / \mathrm{t} \mathrm{CO}_{2}$ if the ETS is introduced in 2030. Moreover, Figure 5 also illustrates that operating flexibility lowers the critical carbon price. For example, the critical carbon price without operating flexibility would be about $215 \mathrm{RMB} / \mathrm{tCO}_{2}$ if ETS is introduced in 2015. This also contributes to explaining why the critical carbon price in our study is lower than in Zhang et al. (2014), who, without allowing for operating flexibility ${ }^{13}$, calculate the critical carbon price to range between $230 \mathrm{RMB} / \mathrm{tCO}_{2}$ and $350 \mathrm{RMB} / \mathrm{tCO}_{2}$.

\footnotetext{
${ }^{13}$ Other differences may be due to differences in the methodologies and the definition of the critical carbon price. In Zhang et al. (2014), a trinomial tree model was employed, and the critical carbon price refers to the price above which immediate investment is optimal. In our study least squares Monte Carlo methods were employed, the critical carbon price refers to the price above which the investment would almost certainly occur (i.e. with $90 \%$ probability), and, especially, the CCS retrofit could occur at any point in time during the whole plant lifetime, i.e. between 2015 and 2050 .
} 
Figure 5. Critical carbon prices support CCS retrofits for the base case carbon price drift rate (4\%) (CCS operating flexibility lowers the critical carbon prices required to support CCS retrofits.)

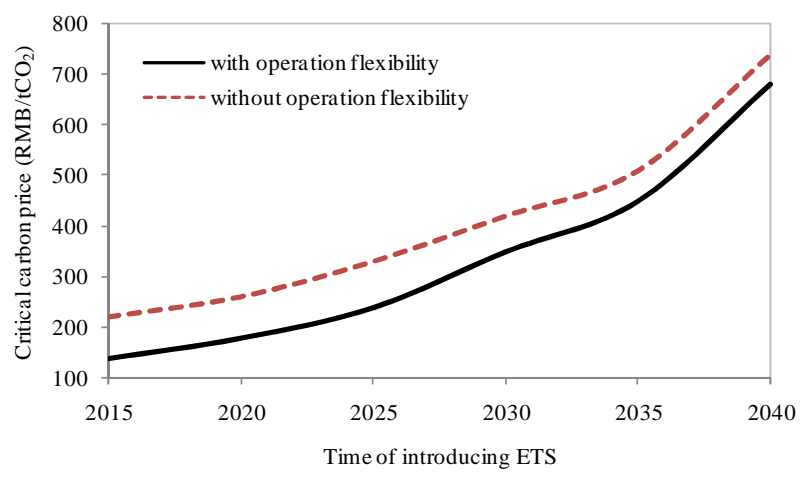

\section{2 $\mathrm{CO}_{2}$ abatement}

Figure 6 shows the probability of achieving a given amount of total emission reductions for the different periods of introducing an ETS when the drift rate of the future carbon price is at its base case level. Table 3 provides the descriptive statistics. Accordingly, the distribution of the amount of $\mathrm{CO}_{2}$ abated is skewed to the left. Notably, the amount of abated $\mathrm{CO}_{2}$ falls between 0 and 10 million metric tons (Mt) in more than $80 \%$ of the simulated paths. For the ETS starting years 2015, $2020,2025,2030,2035,2040,2045,2050$, the probabilities of zero abatement are $60.16 \%$, $61.54 \%, 63.42 \%, 65.58 \%, 69.2 \%, 73.44 \%, 87.24 \%$, and $100 \%$, respectively, though on some paths it approaches $90 \mathrm{Mt} \mathrm{CO}_{2}$ (i.e., the maximum abatement potential corresponding to a mandatory CCS technology standard implemented in $\left.\mathrm{T}_{0}\right) \cdot{ }^{14}$ In most cases, the total amount of abated $\mathrm{CO}_{2}$ does not change much when the ETS is delayed because under the base case assumptions the $\mathrm{CO}_{2}$ price is low relative to the abatement cost, and the amount of $\mathrm{CO}_{2}$ abated is relatively small.

In our model framework, the utility may decide to postpone the CCS retrofit and also chooses whether to operate in CCS mode once a CCS retrofit is implemented. Both types of flexibility decrease the amount of $\mathrm{CO}_{2}$ abated. To explore which type of flexibility contributes more to the decrease in $\mathrm{CO}_{2}$ abatement, we combine the results of the CCS retrofit and $\mathrm{CO}_{2}$ abatement. For example, when the ETS is introduced in 2015, the CCS retrofit mainly occurs before 2025 (in approximately $60 \%$ of all paths) (see Figure 3 ). By comparison, if the utility cannot temporarily suspend CCS operation, the amount of $\mathrm{CO}_{2}$ abated in most simulated paths reaches approximately $70 \mathrm{Mt} \mathrm{CO}_{2}{ }^{15}$ Thus, $\mathrm{CCS}$ operating flexibility contributes to the finding that the amount of $\mathrm{CO}_{2}$ abated is rather small. Furthermore, these results indicate that the carbon price in the base case scenario is too low to support future $\mathrm{CO}_{2}$ abatement.

As expected, the later the ETS is introduced, the lower the amount of $\mathrm{CO}_{2}$ abated. This result is

\footnotetext{
${ }^{14}$ The $\mathrm{CO}_{2}$ abatement amount in each year is approximately $2.8 \mathrm{Mt} \mathrm{CO}_{2}$ when operating in CCS mode. If the CCS retrofit is implemented in $\mathrm{T}_{0}$ and CCS operation continues without being suspended, the $\mathrm{CO}_{2}$ abatement during the whole lifetime of the plant is approximately $89.6 \mathrm{Mt} \mathrm{CO}_{2}\left(2.8 \mathrm{Mt} \mathrm{CO}_{2} \times(35-3)\right)$. Note that it takes three years for the plant construction and the CCS retrofit.

${ }^{15}$ If the CCS retrofit is implemented before 2025, the time left for CCS operation is at least 25 years when there is no CCS operating flexibility, and the total amount of $\mathrm{CO}_{2}$ abated exceeds $25 \times 2.8=70 \mathrm{Mt}_{2}$.
} 
driven by two factors. First, and most obvious, the later the ETS regulation is introduced, the fewer years the utility is incentivized to reduce the $\mathrm{CO}_{2}$ emissions of the plant (because the lifetime of the plant is fixed). Second, a delay in ETS regulation decreases investment in CCS (see section 4.1) and thus decreases $\mathrm{CO}_{2}$ abatement in Stage 3.

Figure 6. Distribution of $\mathrm{CO} 2$ abatements at different times of introducing an ETS for the base case (The amount of $\mathrm{CO} 2$ abated is relatively small and does not change much when the ETS is delayed because the carbon prices in the base case are low relative to the CCS abatement costs.)

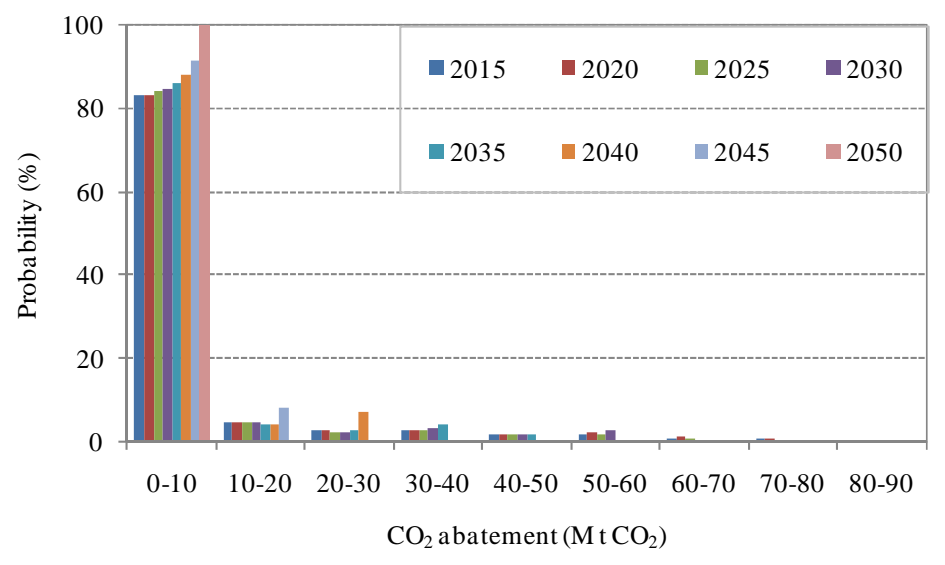

Table 3. Descriptive statistics of $\mathrm{CO} 2$ abatement

\begin{tabular}{lcccccccc}
\hline Time of introducing ETS & 2015 & 2020 & 2025 & 2030 & 2035 & 2040 & 2045 & 2050 \\
\hline Mean $\left(\mathrm{Mt} \mathrm{CO}_{2}\right)$ & 6.5 & 6.2 & 5.8 & 5.0 & 4.0 & 2.8 & 1.3 & 0.0 \\
\hline $\mathrm{SD}(\mathrm{Mt} \mathrm{CO})$ & 16.1 & 15.5 & 14.5 & 12.7 & 10.3 & 7.4 & 3.9 & 0.0 \\
\hline
\end{tabular}

Figure 7 displays the expected amounts of $\mathrm{CO}_{2}$ abated under different carbon price drift rates. Total abatement is rather sensitive to the carbon price, with higher drift rates leading to higher total $\mathrm{CO}_{2}$ abatement. A higher future carbon price renders CCS retrofit in Stage 2 more profitable and also provides a stronger financial incentive to operate the plant in CCS mode in each period during Stage 3. Figure 7 shows that, as expected, for all carbon price scenarios, the $\mathrm{CO}_{2}$ abatement amount decreases, the later the ETS is introduced. In addition, if the carbon price is low (e.g. with a $1 \%$ drift rate), the $\mathrm{CO}_{2}$ abatement will be small and will not change much when delaying the introduction of an ETS because the utility may suspend CCS operation even if the CCS is installed. 
Figure 7. The expected $\mathrm{CO} 2$ abatement for different carbon price drift rates (Higher drift rates lead to higher total $\mathrm{CO} 2$ abatement; the impact of carbon prices on abatement is stronger the earlier the ETS is implemented.)

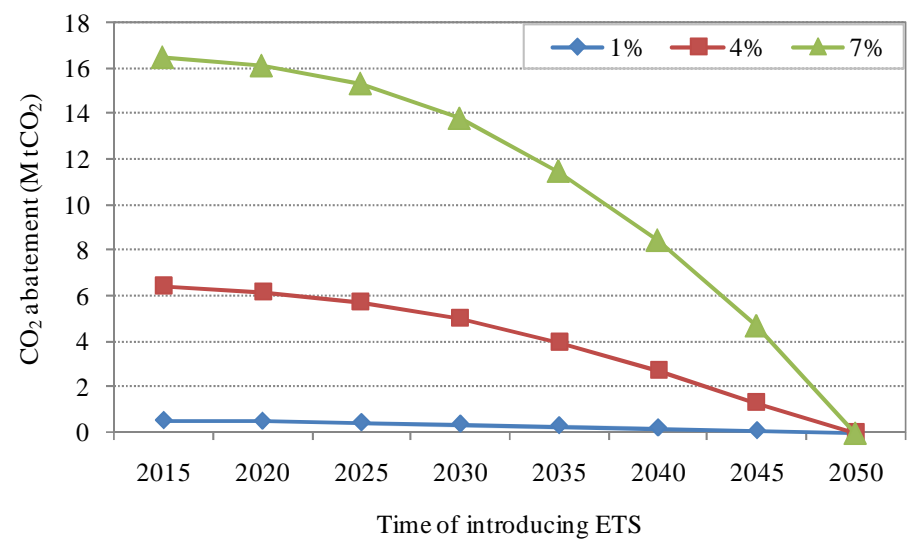

\subsection{Economic value of the power plant investment}

The utility makes its investment decision on the basis of expected NPV. Figure 8 shows the distribution of NPV if the ETS is introduced for the base case in 2030. The shapes of the value distributions when the ETS is implemented in 2015, 2020, 2025, 2040, 2045, and 2050 are similar. ${ }^{16}$ Table 4 provides the key descriptive statistics, suggesting the standard deviation is approximately $10 \%$ of the mean. In addition, the distribution of the economic value is more symmetric than the distribution of the $\mathrm{CO}_{2}$ abatement.

Figure 8. The economic value distribution if the ETS is implemented in 2030 (The distribution of the economic value is more symmetric than the distribution of the $\mathrm{CO} 2$ abatement shown in Figure 6.)

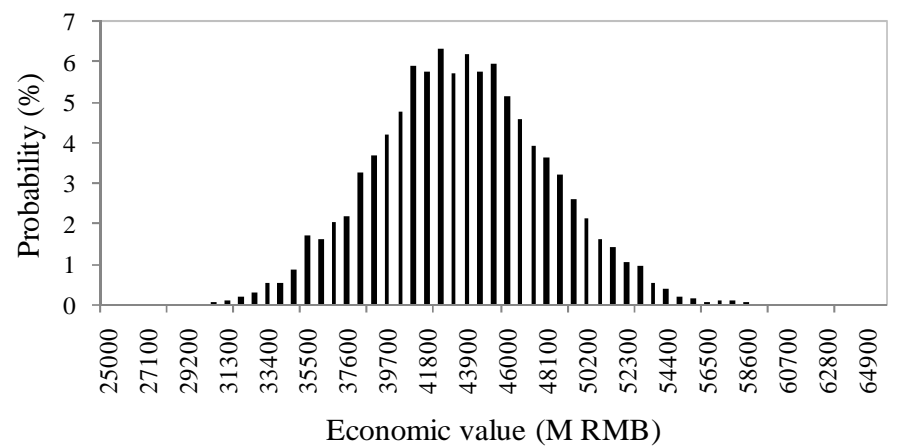

Table 4. Descriptive statistics of the economic value

\begin{tabular}{lcccccccc}
\hline $\begin{array}{l}\text { Time of introducing } \\
\text { ETS }\end{array}$ & 2015 & 2020 & 2025 & 2030 & 2035 & 2040 & 2045 & 2050 \\
\hline Mean (M RMB) & 44760.2 & 44134.9 & 43613.2 & 43270.9 & 43150.2 & 43295.8 & 43787.7 & 44637.9 \\
\hline SD (M RMB) & 4782.8 & 4519.1 & 4495.3 & 4552.8 & 4560.0 & 4614.5 & 4669.4 & 4732.2 \\
\hline
\end{tabular}

\footnotetext{
16 These figures are available on request.
} 
The expected economic values under different carbon price drift rates and points in time to introduce an ETS appear in Figure 9. First, Figure 9 illustrates that higher drift rates lower the economic value of the plant no matter when the ETS is introduced. Higher carbon prices increase compliance costs (i.e., lower the NPV) because the utility has to spend more on purchasing $\mathrm{CO}_{2}$ certificates or to retrofit the plant with CCS and abating $\mathrm{CO}_{2}$. Naturally, the effect of the carbon price becomes smaller the later the ETS is implemented. Second, Figure 9 implies that the pattern of the economic value for different ETS implementation times is U-shaped for lower carbon costs (drift rates of $1 \%$ and $4 \%$ ) and monotonically increasing for higher carbon costs (drift rate of $7 \%)^{17}$.

Figure 9. The expected economic value of the investment with CCS operating flexibility (For low carbon prices the relation between the economic value of the new plant and the length of the delay of the ETS is U-shaped.)
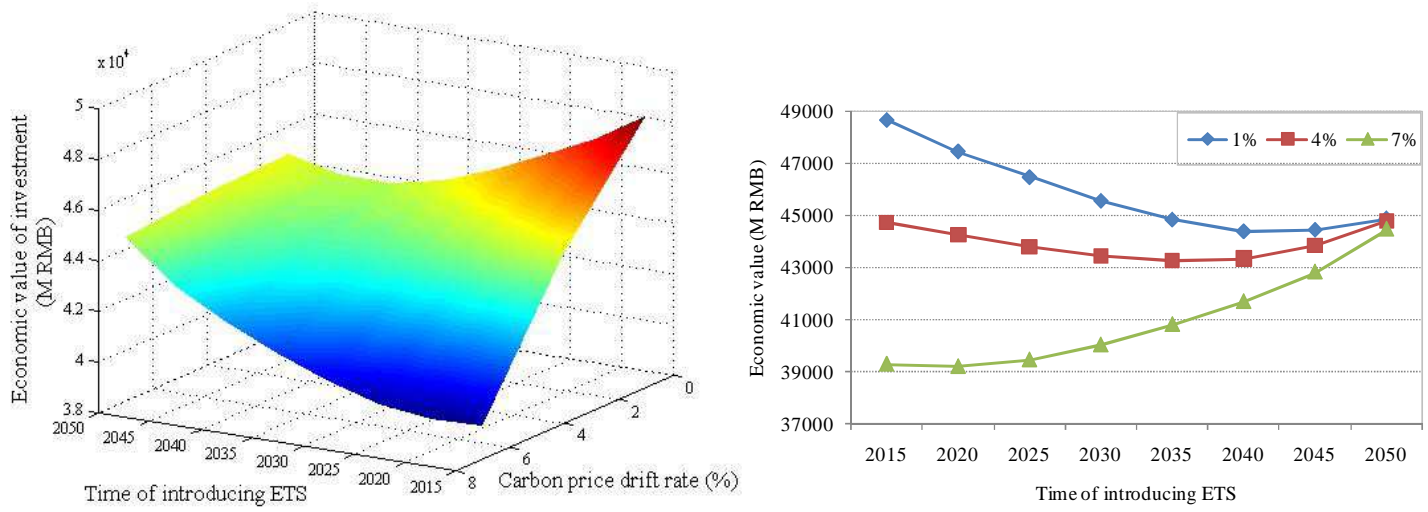

Although arguably counterintuitive at first, this finding may be explained by two countervailing effects. First, delaying the ETS lowers the utility's compliance costs over the lifetime of the plant, thus leading to a higher NPV compared with introducing an ETS in earlier years. Second, the value of the operating flexibility decreases when an ETS is implemented later rather than sooner, leading to a lower NPV. As an illustration, Figure 10 shows the NPV of a plant without CCS operating flexibility, while all other conditions remain the same. Thus, once the investment is made, the plant must run in CCS mode in each period. In this case, the later an ETS is implemented, the higher the NPV of the plant is for all drift rates.

\footnotetext{
${ }^{17}$ For the $4 \%$ carbon price drift rate, the figures in Table 4 also reflect the U-shaped relation between the economic value of a plant and the ETS introduction year, but the effects are rather small. However, Figure 9 suggests, that for the other drift rates, considered the timing of introducing an ETS has a substantial effect on the investment decision. For the $1 \%$ carbon price drift rate, the economic value first decreases from $48662 \mathrm{MRMB}$ to 44401 MRMB (corresponding to a decrease of about 9\%) with the ETS being delayed from 2015 to 2040. In this case, the change in the economic value exceeds the initial investment cost (3 165.8 MRMB). Similarly, for the 7\% carbon price drift rate, the economic value increases from 39303 MRMB to 44781 (corresponding to an increase of about 14\%) with the ETS being delayed from 2015 to 2050.
} 
Figure 10. The expected economic value of the investment without CCS operating flexibility (If there is no operating flexibility, the economic value of the investment increases monotonically with the length of the delay of the ETS.)

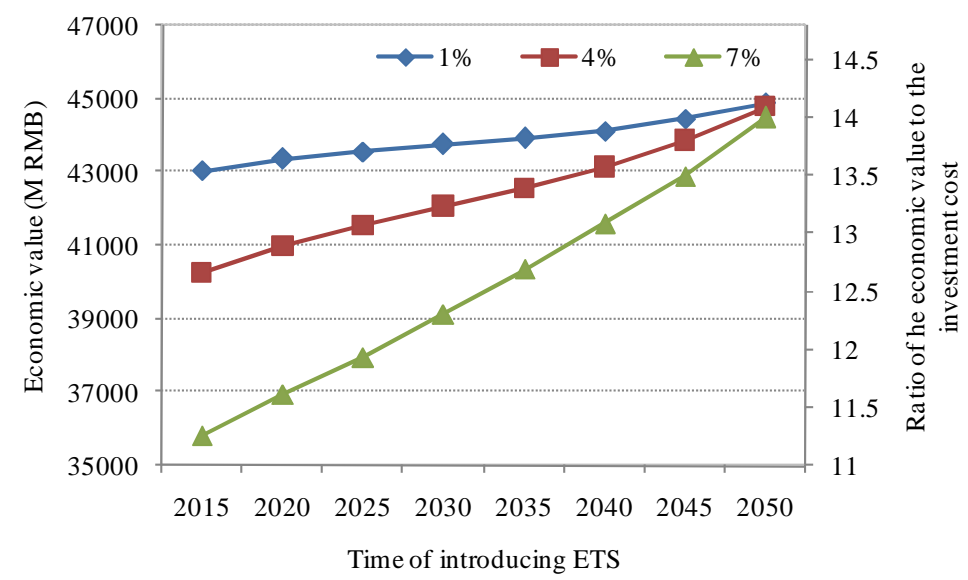

The value of the CCS operating flexibility may then be calculated as the difference between the curves shown in Figure 9 and those in Figure 10 (see Figure 11). Naturally, the economic value with operating flexibility is greater than that without operating flexibility in each carbon price scenario. In addition, the later the ETS is introduced, the smaller is the value of the operating flexibility. Thus, as real options theory suggests (Dixit and Pindyck, 1994), there is a positive correlation between the value of the operating flexibility and the length of time in which the operating flexibility is valid. As Figure 9 shows, for low carbon prices, this negative flexibility effect of delaying the introduction of the ETS on the NPV is larger than the positive compliance cost effect when the delay is short, and vice versa when the delay is long. For higher carbon prices, the compliance cost effect dominates even for a short delay of introducing an ETS.

Figure 11. The value of the operating flexibility at different levels of the carbon price drift rate (The value of the operating flexibility decreases with the length of the delay of the ETS and with the carbon price drift rate.)

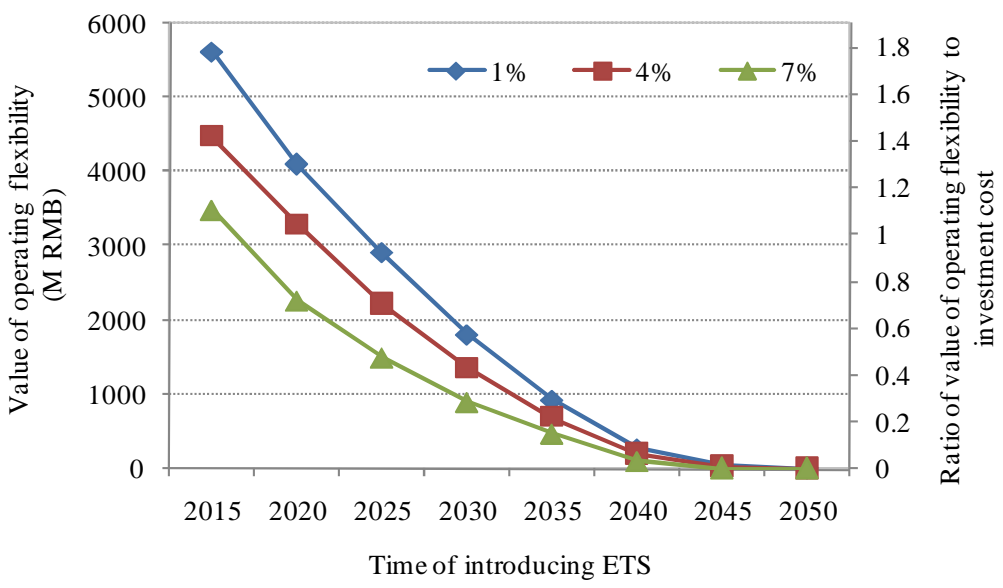




\section{Conclusion}

In many countries, investors face uncertainty about whether and when an ETS will be implemented, yet they have to make decisions about projects before the regulation becomes known. Uncertainty also arises from uncertain input and output prices. Notably, because the prices of $\mathrm{CO}_{2}$ certificates are determined by market conditions, implementing an ETS adds uncertainty for investors. In this article, we rely on real options theory to analyze the effect of the timing of an ETS on power plant CCS retrofit decisions, plant $\mathrm{CO}_{2}$ emissions, and NPV, allowing for uncertainty about input and output prices. In particular, unlike most previous analyses, our multistage decision model accounts for CCS operating flexibility; at each stage, the utility may suspend operating CCS temporarily and instead purchase $\mathrm{CO}_{2}$-certificates on the market

We first find that that operating flexibility lowers the critical carbon price for investment in a CCS plant. Since operating flexibility renders investment in CCS less irreversible, and the propensity to invest in a CCS plant would increase. Our simulation results suggest that in this case the critical carbon price is about $140 \mathrm{RMB} / \mathrm{CO}_{2}$, which is much lower than previously found in literature which relies on models without operating flexibility. Thus, operating flexibility is expected to increase investment in CCS plants even at low certificate prices. In this sense, when the utility or as is often the case in China - the government evaluate CCS investment project in practice, CCS operating flexibility should not be ignored, else the economic viability of CCS investment may be underestimated. The critical carbon price, however, increases when the introduction of the ETS is delayed. Likewise, our results confirm that delaying implementation of an ETS generally reduces a utility's propensity to invest in a CCS retrofit and also lowers the total amount of $\mathrm{CO}_{2}$ abated. For example, if the implementation of an ETS is delayed from 2020 to 2030, the probability of investing in CCS retrofit decreases by approximately 10 percentage points. Naturally, to promote investment in $\mathrm{CCS}$ and $\mathrm{CO}_{2}$ abatement, an ETS would have to be implemented earlier rather than later.

The impact of delaying the introduction of an ETS on $\mathrm{CO}_{2}$ abatement crucially depends on the carbon price. If the future carbon price drift rate is sufficiently high, the delay lowers $\mathrm{CO}_{2}$ abatement significantly. For a low carbon price drift rate, however, the effect on $\mathrm{CO}_{2}$ abatement is small (and smaller than it would be for a CCS plant without flexibility) during the whole lifetime of the plant because plant operators will find it more profitable to run the plant in off-CCS mode and purchase $\mathrm{CO}_{2}$ certificates on the market instead.

Arguably, our interesting insights pertain to the effects of delaying the implementation of an ETS on the net present value of the plant when there is operating flexibility. First, delaying the ETS lowers the utility's compliance costs over the lifetime of the plant and thus increases the NPV of the project. Second, allowing for operating flexibility increases the NPV of the plant. The longer the time in which operating flexibility is valid (i.e., the shorter the delay of the ETS), the more valuable is operating flexibility. As expected, we find that for sufficiently high carbon price drift rate, delaying the ETS always improves the NPV. For sufficiently low carbon price drift rate however, this relationship is U-shaped: When the delay time is short, the value of the operating flexibility is high and outweighs the compliance cost effect (i.e., the NPV declines when the ETS is delayed). For longer delay times, we observe the reverse. While investors typically prefer 
regulations such as an ETS to be introduced later rather than sooner, our findings suggest that such a delay may not be in their best interest when $\mathrm{CO}_{2}$ certificate prices are low. In practice, $\mathrm{CO}_{2}$ certificate prices in China (and elsewhere) are likely to be moderate, at least initially, reflecting rather modest greenhouse gas emission targets.

The CCS operating flexibility also means that direct support for investments in CCS plants or for CCS retrofitting does not necessarily result in lower $\mathrm{CO}_{2}$ emissions. If the future $\mathrm{CO}_{2}$ certificate prices are too low, the utility may be better off purchasing allowances rather than operating in CCS mode and thereby incurring a loss in production efficiency. In this case, subsidizing a CCS retrofit may not necessarily lower a plant's emissions unless accompanied by additional measures to ensure a high expected carbon price. Such mechanisms include floor prices, as currently implemented for auctions in the regional ETS in California, Quebec, or the Regional Greenhouse Gas Initiative (RGGI), or a market stability reserve mechanism which will be implemented in the EU ETS from 2019 on.

In addition to $\mathrm{CO}_{2}$ certificate prices, other factors influence investments in CCS, CCS retrofits, and the operation of a CCS plant, and, thus, also influence the effect of delays in implementing an ETS. For example, the costs of CCS retrofits may decline over time because of learning effects. In this case, delaying an ETS would not necessarily lower CCS investments. Likewise, if fuel prices increase significantly, the costs of operating the plant in CCS mode increase, resulting in lower CCS investment and less CCS mode operation. Similarly, introducing an ETS may also affect the electricity and coal markets, which, in turn, may influence the investment and operating decisions of CCS plants. While considering these indirect effects may be called for in a longer-term analysis, they are omitted from our analysis because they are likely to be negligible in the short-to-medium term. First, since the electricity market in China is still regulated, higher carbon costs do not necessarily lead to a corresponding increase in electricity prices. Second, the carbon price in China's current pilot systems is relatively low, and will probably not be high in the short-tomedium term in a future national system, since the size of the emission budget is likely to reflect China's prioritization of economic growth. Finally, in our analysis, the carbon price evolution was assumed to be exogenously stochastic, and we neglected the effect of introducing $\mathrm{CO}_{2}$ emission regulation on the overall future carbon price evolution. However, the future carbon price may depend on the timing of previous policy decisions. In this case, delaying the implementation of an ETS would lead to higher carbon prices in the future so that a given future climate target may be met. Further research could analyze the impact of endogenous carbon prices on investment in power plant CCS retrofits, and CCS plant operation.

Finally, although this paper is motivated by the actual policy environment in China and the simulations are based on parameter values for a supercritical pulverized coal power plant in China, the findings may easily be transferred to investment in CCS plants in other countries where the timing of the introduction of ETS is uncertain.

\section{Acknowledgments}

We are thankful for the insightful comments provided by three anonymous reviewers. The paper also benefitted from suggestions made by seminar participants at CEEP in CAS. Part of this 
research was conducted while Jian-Lei Mo was a guest researcher at Fraunhofer Institute for Systems and Innovation Research (Fraunhofer ISI). Finally, we acknowledge support from the National Natural Science Foundation of China under Grant numbers 71403263 and 71210005.

\section{References}

Abadie, L.M., Chamorro, J.M., 2008. European $\mathrm{CO}_{2}$ prices and carbon capture investments. Energy Economics 30(6), 2992-3015.

Alberola, E., Chevallier, J., Cheze, B., 2008. Price drivers and structural breaks in European carbon prices 2005-2007. Energy Policy 36(2), 787-797.

Benz, E., Trück, S., 2009. Modeling the price dynamics of $\mathrm{CO}_{2}$ emission allowances. Energy Economics 31(1), $4-15$.

Blyth, W., Bradley, R., Bunn, D., Clarke, C., Wilson, T., Yang, M., 2007. Investment risks under uncertainty. Energy Policy 35(11), 5766-5773.

Brauneis, A., Mestel, R., Palan, S., 2013. Inducing low-carbon investment in the electric power industry through a price floor for emissions trading. Energy Policy 53, 190-204.

Chalmers, H., Lucquiaud, M., Gibbins, J., Leach, M., 2009. Flexible operation of coal fired power plants with postcombustion capture of carbon dioxide. Journal of Environmental Engineering 135, 449-458.

Chen, W., Xu, R., 2010. Clean coal technology development in China. Energy Policy 38(5), 2123-2130.

Davis, G., Owens, B., 2003. Optimizing the level of renewable electric R\&D expenditures using real options analysis. Energy Policy 31(15), 1589-608.

Davison, J., 2007. Performance and costs of power plants with capture and storage of $\mathrm{CO}_{2}$. Energy 32(7), $1163-1176$

Deng, J., 2008. Adopting clean and high-efficiency power generation technologies vigorously to promote the sustainable development of electric power industry. Huadian Technology 30(1), 1-4.

Dixit, A.K., Pindyck, R.S., 1994. Investment under uncertainty. Princeton University Press, Princeton, NJ.

Fan, Y., Mo, J.L., Zhu, L., 2013. Evaluating coal bed methane investment in China based on a real options model. Resource Policy 38(1), 50-59.

Fleten, S., Näsäkkälä, E., 2010. Gas-fired power plants: Investment timing, operating flexibility and $\mathrm{CO}_{2}$ capture. Energy Economics 32(4), 805-816.

Fuss, S., Szolgayova, J., Obersteiner, M., Gusti, M., 2008. Investment under market and climate policy uncertainty. Applied Energy 85(8), 708-721.

Hirschhausen, C., Herold, J., Oei, P-Y., 2012 How a "low carbon' innovation can fail: tales from a "lost decade" for carbon capture, transport, and sequestration (CCTS). Economics of Energy \& Environmental Policy 1(2).

Huang, Q.L., 2008. Clean and highly effective coal-fired power generation technology in China. Huadian Technology 30(3), 1-8

IEA, 2007a. Climate policy uncertainty and investment risk. OECD/IEA, France.

IEA, 2007b. World Energy Outlook. OECD/IEA, France.

IEA, 2010. Reviewing existing and proposed emissions trading systems. OECD/IEA, France.

IEA, 2013a. $\mathrm{CO}_{2}$ emissions from fuel combustion. OECD/IEA, France.

IEA, 2013b. World energy outlook. OECD/IEA, France.

IEA, 2015. Energy Technology Perspectives 2015. OECD/IEA, France.

Jotzo, F., 2013. Emissions trading in China: principles, design options and lessons from international practice. 
CCEP Working Paper 1303.

Kumbaroğlu, G., Madlener, R., Demirel, M., 2008. A real options evaluation model for the diffusion prospects of new renewable power generation. Energy Economics 30(4), 1882-1908.

Liang, X., Reiner, D., Gibbins, J., Li, J., 2009. Assessing the value of $\mathrm{CO}_{2}$ capture ready in new-build pulverised coal-fired power plants in China. International Journal of Greenhouse Gas Control 3(6), 787-792.

Longstaff, F., Schwartz, E., 2001. Valuing American options by simulation: a simple least-squares approach. Review of Financial Studies 14(1), 113-147.

Markusson, N., Haszeldine, S., 2010. "Capture ready" regulation of fossil fuel power plants: betting the UK's carbon emissions on promises of future technology. Energy Policy 38(11), 6695-6702.

Mo, J.L., Li, Y., Zhu, L., 2013. The impact of potential climate policy on the coal bed methane investment in China: a real option-based study. International Journal of Global Energy Issues 36(2/3/4), 96-115.

Mo, J.L., Zhu, L., 2014. Using floor price mechanisms to promote carbon carbon capture and storage (CCS) investment and $\mathrm{CO}_{2}$ abatement. Energy and Environment 25(3/4), 687-707.

National Development and Reform Commission (NDRC), 2011. The notice on the carbon emissions trading pilot work in China. http://www.ndrc.gov.cn/zcfb/zcfbtz/2011tz/t20120113_456506.htm.

National Development and Reform Commission (NDRC), 2012. China's policies and actions for addressing climate change (2012). http://qhs.ndrc.gov.cn/zcfg/W020121122588539459161.pdf.

People's Republic of China (PRC), 2011. The Twelfth Five-Year Plan for national economic and social development of the People's Republic China. http://www.gov.cn/2011lh/content_1825838.htm.

Pindyck, R.S., 1999. The long-run evolution of energy prices. The Energy Journal 20(2), 1-27.

Rohlfs, W., Madlener, R., 2011.Valuation of CCS-ready coal-fired power plants: a multi-dimensional real options approach. Energy Systems 2(3/4), 243-261.

Schwartz, E., Smith J.E., 2000. Short-term variations and long-term dynamics in commodity prices. Management Science 46(7), 893-911.

Sekar, R.C., 2005. Carbon dioxide capture from coal-fired power plants: a real options analysis. Master's Thesis, Massachusetts Institute of Technology.

Siddiqui, A.S., Marnay, C., Wiser, R.H., 2007. Real options valuation of US federal renewable energy research, development, demonstration, and deployment. Energy Policy 35(1), 265-279.

Walsh, D.M., O'Sullivan, K., Lee, W.T., Devine, M.T., 2014. When to invest in carbon capture and storage technology: A mathematical model. Energy Economics 42, 219-225.

Wang, W., 2012. Overview of climate change policies and prospects for carbon markets in China. Les Cahiers de la Chaire Economie du Climat, Information and Debates Series.

The World Bank, 2014. The state and trends of the carbon pricing. The World Bank, Washington DC.

Xun, B., Wen, F., Li, X., Wen, A. \& Fu, C. 2014. Generation investment decision-making in emission trading environment with multiple uncertainties. Dianli Xitong Zidonghua/Automation of Electric Power Systems, 38, 51-56.

Yang, M., Blyth, W., Bradley, R., Bunn, D., Clarke, C., Wilson, T., 2008. Evaluating the power investment options with uncertainty in climate policy. Energy Economics 30(4), 1933-1950.

Zhang, X., Li, W., 2011. Power producer's carbon capture investment timing under price and technology uncertainties. Energy Procedia 5, 1713-1717.

Zhang, X., Wang, X., Chen, J., Xie, X., Wang, K., Wei, Y., 2014. A novel modeling based real options approach for CCS investment evaluation under multiple uncertainties. Applied Energy 113, 1059-1067.

Zhou, W., Zhu, B., Fuss, S., Szolgayová, J., Obersteiner, M., Fei, W, 2010. Uncertainty modeling of CCS investment strategy in China's power sector. Applied Energy 87(7), 2392-2400. 
Zhu, L., Fan, Y., 2011. A real options-based CCS investment evaluation model: case study of China's power generation sector. Applied Energy 88(12), 4320-4333. 


\section{Appendix A: Calculation of cash flow and $\mathrm{CO}_{2}$ abatement}

The cash flow in each period $C F$ can be expressed as

$$
C F=R_{e}-C_{\text {fuel }}-C_{o m}-C_{T S}-C_{C O_{2}}
$$

where $R_{e}$ is the revenues from the electricity sales, $C_{\text {fuel }}$ is the fuel cost, $C_{o m}$ stands for the costs of operation and maintenance $(\mathrm{O} \& \mathrm{M}), C_{T S}$ reflects the costs for transportation and sequestration of $\mathrm{CO}_{2}$, and $\mathrm{C}_{\mathrm{CO}_{2}}$ is the costs for acquiring $\mathrm{CO}_{2}$ certificates. We assume that no certificates are allocated for free. In addition, the utility takes prices in all input and output markets as given.

Before the ETS is introduced(BETS), $C_{T S}=C_{\mathrm{CO}_{2}}=0$, and

$$
C F_{i}^{B E T S}=R_{e-i}^{B E T S}-C_{f u e l-i}^{B E T S}-C_{o m-i}^{B E T S}
$$

After the ETS is introduced and before the plant is retrofitted with $\mathrm{CCS}(\mathrm{BR}), \mathrm{C}_{\mathrm{CO}_{2}}>0$, and

$$
C F_{i}^{B R}=R_{e-i}^{B R}-C_{f u e l-i}^{B R}-C_{o m-i}^{B R}-C_{C_{2}-i}^{B R} .
$$

After the ETS is introduced and the plant is retrofitted with CCS, operating the plant in CCS mode (CC) means lower revenues from electricity sale, higher costs for O\&M, and additional costs for transportation and sequestration but lower costs for acquiring certificates. In this case,

$$
C F_{i}^{C C}=R_{e-i}^{C C}-C_{f u e l-i}^{C C}-C_{o m-i}^{C C}-C_{T S-i}^{C C}-C_{C_{2}-i}^{C C} \text {. }
$$

If the utility suspends CCS (SCC), costs for O\&M are lower and $C_{T S}=0$, but certificate costs are higher. Therefore,

$$
C F_{i}^{S C C}=R_{e-i}^{S C C}-C_{f u e l-i}^{S C C}-C_{o m-i}^{S C C}-C_{C O_{2}-i}^{S C C}
$$

The utility can sell the same amount of electricity $N_{e}^{N C C S}$ in non-CCS mode as before the CCS retrofit, such that its revenues are

$$
R_{e-i}^{B E T S}=R_{e-i}^{B R}=R_{e-i}^{S C C}=N_{e-i}^{N C C S} \times P_{e-i},
$$

where $P_{e-i}$ is the electricity price in period i. Operating in CCS mode leads to lower electricity generation than $N_{e}^{N C C S}$, so revenue is

$$
R_{e-i}^{C C}=N_{e-i}^{C C S} \times P_{e-i} .
$$


In each scenario, the fuel input (coal consumption) is the same, $N_{c o}$. Thus, fuel costs are

$C_{\text {fuel- } i}^{B E T S}=C_{\text {fuel-i }}^{B R}=C_{\text {fuel }-i}^{S C C}=C_{\text {fuel }-i}^{C C}=N_{c o-i} \times P_{c o-i}$,

where $P_{c o-i}$ is the price of coal in period i. The $\mathrm{CO}_{2}$ emissions are $N_{\mathrm{CO}_{2}}^{N C C S}$ before a CCS retrofit and also after a CCS retrofit under non-CCS operation mode. The costs of acquiring certificates are then

$C_{\mathrm{CO}_{2}-i}^{\mathrm{BR}}=C_{\mathrm{CO}_{2}-i}^{\mathrm{SCC}}=\mathrm{N}_{\mathrm{CO}_{2}-i}^{\mathrm{NCCS}} \times P_{\mathrm{CO}_{2}-i}$,

where $P_{\mathrm{CO}_{2}-i}$ is the carbon price in period i.

In CCS operation mode, the $\mathrm{CO}_{2}$ emission $N_{C O_{2}}^{C C S}<N_{C O_{2}}^{N C C S}$, and

$C_{\mathrm{CO}_{2}-i}^{\mathrm{CC}}=\mathrm{N}_{\mathrm{CO}_{2}-i}^{\mathrm{CCS}} \times P_{\mathrm{CO}_{2}-i}$

Note that $N_{\mathrm{CO}_{2}}^{C C S}>0$, reflecting a capture rate of less than $100 \%$. The amount of $\mathrm{CO}_{2}$ abated under CCS mode, $N_{C A A}$, is then

$N_{C A A}=N_{C O_{2}}^{S C C}-N_{\mathrm{CO}_{2}}^{C C}$.

In CCS mode, the costs for $\mathrm{CO}_{2}$ transportation and sequestration are

$C_{T S}^{C C}=c_{T S}^{C C} \times N_{C A A}$,

where $c_{T S}^{C C}$ is the per unit costs of $\mathrm{CO}_{2}$ transportation and sequestration.

Before the plant is retrofitted with $\mathrm{CCS}, \mathrm{CO}_{2}$ abatement is 0 ; after the plant is retrofitted, it is $N_{C A A}$ in CCS operation mode and 0 in non-CCS operation mode. Thus, the $\mathrm{CO}_{2}$ abatement amount in period $i, N_{C}{ }^{i}$, can be described by

$$
\left.N_{C}{ }^{i}=\left\{\begin{array}{lr}
0, & \text { when } T_{0} \leq i \leq T_{r} \\
0, & \text { if } C F_{i}^{S C C} \geq C F_{i}^{C C} \\
N_{C A A}, & \text { if } C F_{i}^{S C C}<C F_{i}^{C C}
\end{array}\right\} \text { when } T_{r}<i \leq T\right\} \text {. }
$$

The total amount of $\mathrm{CO}_{2}$ abated during the lifetime of the plant is

$$
N=\sum_{i=T_{0}}^{T} N_{C}{ }^{t}
$$




\section{Appendix B: Modeling price uncertainty}

The evolution of prices can be described as follows:

$d P_{i-t}=\alpha_{i} P_{i-t} d t+\sigma_{i} P_{i-t} d W_{i-t}$

where $i=1,2,3$, and $P_{1-t}, P_{2-t}$, and $P_{3-t}$ represent the coal price, electricity price, and carbon price, respectively; $\alpha_{i}$ stands for the price drift rate; $\sigma_{i}$ is the instantaneous price volatility; and $d W_{i-t}$ is the increment to a standard Wiener process, assumed to be normally distributed with zero mean and variance $d t$. Because the utility is assumed to be risk neutral, the risk-adjusted form of the process is:

$d P_{i-t}=\left(\alpha_{i}-\lambda_{i}\right) P_{i-t} d t+\sigma_{i} P_{i-t} d W_{i-t}$,

where $\lambda_{i}$ is the risk premium, and $\left(\alpha_{i}-\lambda_{i}\right)$ is the risk-adjusted drift rate.

Let $X_{i-t}=\ln \left(P_{i-t}\right)$; applying Ito's lemma yields,

$d X_{i-t}=\left(\alpha_{i}-1 / 2 \sigma_{i}^{2}-\lambda_{i}\right) d t+\sigma_{i} d W_{i-t}$.

In the simulations in Section 4, we used the discrete approximation:

$P_{i-(t+1)}=P_{i-t} \exp \left[\left(\alpha_{i}-1 / 2 \sigma_{i}^{2}-\lambda_{i}\right) \Delta t+\sigma_{i}(\Delta t)^{1 / 2} \varepsilon_{t}\right]$.

To allow for correlations of the evolution of the electricity price, the coal price, and the carbon price, we added the following conditions (see Dixit and Pindyck, 1994):

$\left\{\begin{array}{l}d W_{1-t} d W_{2-t}=\rho_{1-2} d t, \\ d W_{1-t} d W_{3-t}=\rho_{1-3} d t, \\ d W_{2-t} d W_{3-t}=\rho_{2-3} d t .\end{array}\right.$

where $\rho_{1-2}, \rho_{1-3}$, and $\rho_{2-3}$ are the coefficients of correlation, which reflect the extent to which both series move together beyond their trends. 


\section{Appendix C: Model solution}

We employed a least squares Monte Carlo simulation method to improve the accuracy of the estimation of $E_{t}\left(V_{t}^{1}\right), E_{t}\left(V_{t}^{2}\right), E_{t}\left(V_{t}^{3}\right)$, and $E_{t}\left(N P V_{t}\right)$. To begin, we regressed the economic values $\left(V_{t}^{1}, V_{t}^{2}, V_{t}^{3}\right.$ and $\left.N P V_{t}\right)$ on a linear combination of a set of basic functions of stochastic variables (electricity price $P_{e l-t}$, coal price $P_{c o-t}$, and carbon price $P_{c a-t}$ ):

$$
\left\{\begin{array}{c}
V_{t}^{i}=a_{i}+b_{i} P_{c o-t}+c_{i} P_{e l-t}+d_{i} P_{c a-t}+e_{i} P_{c o-t}^{2}+f_{i} P_{e l-t}^{2}+g_{i} P_{c a-t}^{2} \\
+h_{i} P_{c o-t} \mathrm{~g} P_{e l-t}+k_{i} P_{c o-t} \mathrm{~g} P_{c a-t}+l_{i} P_{c a-t} \mathrm{~g} P_{e l-t}+\varepsilon_{i-t},(i=1,2,3) \\
N P V_{t}=a_{4}+b_{4} P_{c o-t}+c_{4} P_{e l-t}+d_{4} P_{c a-t}+e_{4} P_{c o-t}^{2}+f_{4} P_{e l-t}^{2}+g_{4} P_{c a-t}^{2} \\
\quad+h_{4} P_{c o-t} \mathrm{~g} P_{e l-t}+k_{4} P_{c o-t} \mathrm{~g} P_{c a-t}+l_{4} P_{c a-t} \mathrm{~g} P_{e l-t}+\varepsilon_{4-t}
\end{array} .\right.
$$

Relying on the estimated regression parameters $\left(a_{i}, b_{i}, c_{i}, d_{i}, e_{i}, f_{i}, g_{i}, h_{i}, k_{i}, l_{i} ; i=1,2,3,4\right.$. $)$ and the simulated stochastic variables, we calculated the estimator for the expected economic value $\left[E_{t}\left(V_{t}^{1}\right), E_{t}\left(V_{t}^{2}\right), E_{t}\left(V_{t}^{3}\right)\right.$, and $\left.E_{t}\left(N P V_{t}\right)\right]:$

$$
\left\{\begin{array}{c}
E_{t}\left(V_{t}^{i}\right)=a_{i}+b_{i} P_{c o-t}+c_{i} P_{e l-t}+d_{i} P_{c a-t}+e_{i} P_{c o-t}^{2}+f_{i} P_{e l-t}^{2}+g_{i} P_{c a-t}^{2} \\
+h_{i} P_{c o-t} \mathrm{~g} P_{e l-t}+k_{i} P_{c o-t} \mathrm{~g} P_{c a-t}+l_{i} P_{c a-t} \mathrm{~g} P_{e l-t},(i=1,2,3) ; \\
E_{t}\left(N P V_{t}\right)= \\
a_{4}+b_{4} P_{c o-t}+c_{4} P_{e l-t}+d_{4} P_{c a-t}+e_{4} P_{c o-t}^{2}+f_{4} P_{e l-t}^{2}+g_{4} P_{c a-t}^{2} \\
+h_{4} P_{c o-t} \mathrm{~g} P_{e l-t}+k_{4} P_{c o-t} \mathrm{~g} P_{c a-t}+l_{4} P_{c a-t} \mathrm{~g} P_{e l-t}
\end{array} .\right.
$$

To check robustness of the results, we also included the higher orders of the stochastic variables. Doing so significantly increased processing time, but the results hardly changed. 